\title{
Physical-Chemical Analysis of Miter Glass Element Decoration
}

\author{
E. Greiner-Wronowa ${ }^{a, *}$ AND B. KALFAS ${ }^{b}$ \\ ${ }^{a}$ Faculty of Materials Science and Ceramics, Technical University of Science and Technology \\ al. A. Mickiewicza 30, 30-059 Kraków, Poland \\ ${ }^{b}$ Conservation Laboratory at the Wawel Cathedral, Wawel 5, 31-001 Kraków, Poland
}

(Received March 17, 2012)

\begin{abstract}
This paper refers to the glass elements, belonging to the XIIIth c. miter, called Saint Stanisław from the Wawel Cathedral Museum in Kraków. The miter so-called Saint Stanisław, has been one of small number preserve miters preserved in Europe, and only one Romanesque style bishop miter in Poland. According to decoration composition is very close to the miter of Calvo bishop (1180-1243) from Diocese Museum in Vic. There were decorative motives, created by embroidering by blue glass beads, and surrounding them by gold thread. The exposition conditions have had fundamental meaning on the miter stage. The glass elements from St. Stanisław's miter were analyzed to solve problem of the place of the miter exposition. It was realized by estimation of glass corrosion category. Moreover, obtained data could help to confirm the hypothesis of displaying it on the altar, which was expected by the historians to their historical documentation. That kind of the XIIIth c. material analyses have never been done before.
\end{abstract}

PACS: $81.40 . \mathrm{Np}, 81.65 . \mathrm{Kn}$

\section{Introduction}

The XIIIth c. miter pretiosa - connected with St. Stanisław (Kraków bishop 1072-1079) — has been stored at the treasure house of the Archdiocese Museum at the Wawel Castle in Kraków (Poland). At the time of St. Stanisław's death Polish bishops have not got the privilege to use miter, bestowed by the pope. There are no earlier source information about this subject. The miter has not been mentioned in the first inventories of Kraków cathedral from A.D. 1101 and 1110.

According to contemporary knowledge, the miter origin is connected with St. Stanisław canonization ceremony in Assisi (17.IX.1253), or after canonization ceremony in Kraków (1242). That miter could be ordered for this solemnity by Kraków bishop Prandota in 1242 . Precisely description of miter has been presented in the inventory book dated on 1563 . It was introduced as a note in reliquary register. The miter has been treated as an genuine souvenir after St. Stanisław.

Taking into consideration the historical value of this object any conservation activity must be minimized and very well done. But because of its stage some supplements have to be done to preserve this object. Moreover, the way of exposition should be taken into consideration, especially hem of miter had to be reinforced, without any touching original fabric hems [1].

\section{Experimental}

On the base of the XIXth c. descriptions, the miter has been preserved in treasure cabinet without any protection. Finally special silver etui was done in 1731 . It

\footnotetext{
* corresponding author; e-mail: egrwrona@agh.edu.pl
}

was changed in1881 for triangle shape glass box. It has made possibility to observe the miter from both side. The miter was there up to 2007 [1].

The technical and technological analysis were carried out. Up to 2007 realized tests have not delivered any information about origin place as well as its prediction. There is question, if the miter was used as a reliquary box decoration or was exposed during some liturgical services.

Glass elements, used for miter decorations were analyzed to solve a problem of the place for the miter exposition. It was realized by estimation of glass corrosion category. Moreover, obtained data could help to confirm the hypothesis of displaying it on the altar. This was expected by the historians to their historical documentation. The glass produced in the XIIIth c. was not the best quality. It was a good example of material vulnerable to deteriorate, due to specific local microclimate. The miter was decorated by glass beads, too. The Department of Glass Technology and Amorphous Coatings in cooperation with the Archdiocese Museum, Wawel Cathedral, Cracow has undertaken some aspect of analyzing some historical glass objects. The glass beads belonging to the miter, called St. Stanisław, were tested - Fig. 1.

The miter in the Roman Catholic Church is very solemn headgear for bishops and abbots. It consists of two triangles (cornu tituli) joined by a simple band and circulus with two hang bands on the back side (fanonones).

The history of glass beads has been very long, and actually they were treated from the very beginning as a first glass product production. Polish glass production has been known since the Xth c. It is connected with many imported materials. The glass beads are very differentiated, but even that, in some cases there are similarities among them [2]. The beads from miter are very simple, spherical round shape, with visible central hole. 


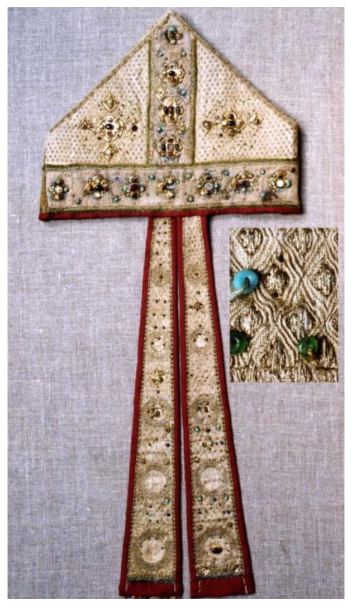

Fig. 1. Miter called St. Stanisław.

Taking into consideration the shape of first beads, miter decorations represented technology on the higher level. The first ones were attached to the fabric by threat, or attached by surrounding glass by threat and sewed to the fabric. Most of them did not have the hole inside, and represented irregular shape. Their color was deep dark, and they do not look like transparent glass.

Glass beads (corals) from miter are very small, but represent good uniformly spread color and the hole was placed almost in the middle. This confirms that analyzed beads are made by high developed technology. It is hard to estimate origin of this production. Probability that it was produced in Poland is the same as suggestion about their foreign production. It should be emphasized here that during XIIIth c. there were many international roads, which were crossing Poland. It was a reason for easy exchanging different goods, including glass. This fact should not be neglected and confirms that many glass products could be treated as an import.

It is very probable that after using miter by bishop (bishops) it was assigned for decoration of the reliquary. It is mentioned in the guide book from 1603 [1]. The miter, being so close with relics, has been became relic. That is why was enclosed into the inventory book in 1563, as an original souvenir after St. Stanisław, Kraków bishop.

Exposition of miter on the altar has been proved, by detecting some spots of wax on the whole object surface, even cornu tituli. The wax drops were fallen down, especially close to monilies [3].

This paper is focused mainly on analyzed decoration elements, which look like a glass. The blue glass beads were analyzed. They were not attached to the miter, because of the broken thread used to attach them to the base (fabric). The two beads and some very tiny fragments of other blue ones were sent to the AGH - Technical University of Science and Technology, Department of Glass Technology and Amorphous Coatings, where the physical and chemical measurements have been carried out.
The main idea of analyzing this material was to prove the hypothesis that miter was displayed on the altar. It was due to the habit of using the miter, for decoration of saint person head relics. The bead tests were done by non-destructive methods, which allow to return original ones on the miter again. It means without any sample coatings. The following methods were used: scanning electron microscopy (SEM), energy dispersive spectroscopy (EDS), Fourier transform infrared (FTIR) and atomic force microscopy (AFM).

\section{Macroscopic observations}

Actually, testing of the bead material has been our main goal. First of all, macroscopic observations were done.

The miter in Fig. 1 has the following dimensions: length $64 \mathrm{~cm} \times$ width $28 \mathrm{~cm} \mathrm{[1].} \mathrm{It} \mathrm{is} \mathrm{made} \mathrm{of} \mathrm{silk,} \mathrm{linen,}$ entwined thread with gold, silver and metal, some jewellery stone, little pearls and turquoise and glass round shape beads with hole. The sides of the miter and circulus titulus are decorated by embroidery of gold and silk thread. The fundamental and the most difficult task was connected with the cleaning of the fabric used for the miter. But, process was done properly. Moreover, it should be emphasized here that the range of conservation activities was dependent on the systematic approach to successive fabric layers used for miter production to avoid damaging any original seams.

Chosen beads (corals) were analyzed. They are round, irregular shape, with whole, made inside, to easier attach them to the fabric. It was provement of high level of bead production.

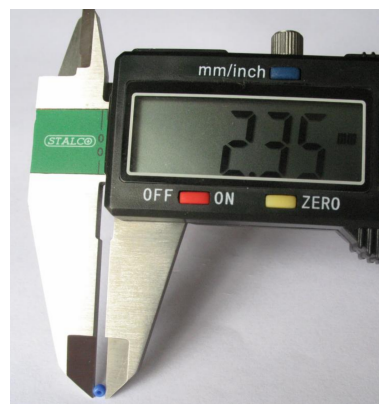

Fig. 2. Measurement of dimensions of the bead.

The dimensions were measured and presented in Fig. 2.

\section{Infrared spectroscopy analysis}

Obtained crushed bead pieces from miter, which were impossible to mend together have been analysed. Remains from blue beads were tested by FTIR to confirm the material structure character of the applied decoration. This technique resolved a spectral feature which 
helps to interpret the classical glass corrosion mechanism. Generally speaking, glass corrosion occurs primarily by two mechanisms: leaching and network dissolution. During the early stages of corrosion the de-alkalisation process is dominant. But, network dissolution was very strongly influenced on the silica-oxygen doublet. The main $\mathrm{Si}-\mathrm{O}-\mathrm{Si}$ and $\mathrm{Si}-\mathrm{O}^{-}$peaks can be gradually shifted as proof of the advanced corrosion process. But, due to the leaching process, the form of $\mathrm{H}_{3} \mathrm{O}^{+}$ and/or $\mathrm{H}_{2} \mathrm{O}$ diffuses into the glass and creates a band at $3300-3500 \mathrm{~cm}^{-1}$. This result points to glass deterioration due to water activity. The leached layer, rich in $\mathrm{SiO}_{2}$ and deficient in alkali, is left with silanol ( $\left.\mathrm{Si}-\mathrm{OH}\right)$ group, after the leaching process started. The structure of the created outside layer has been compared to the silica gel $[4,5]$.

FTIR measurements were realized on an instrument called FTS Digilab60 BioRad and are presented in Fig. 3.

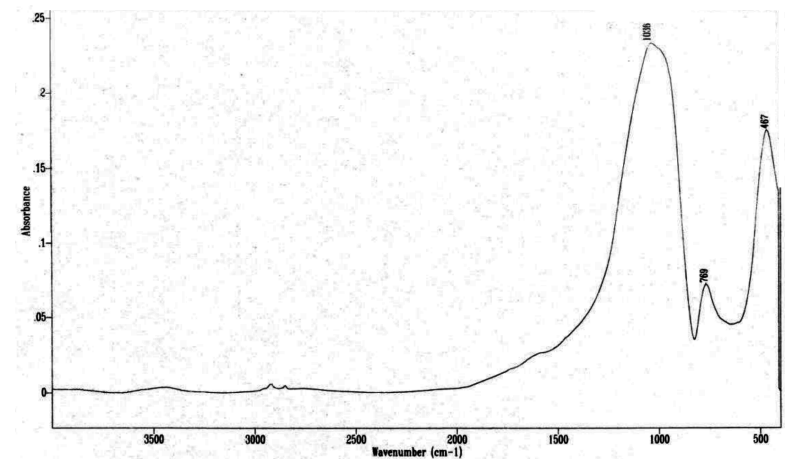

Fig. 3. FTIR spectra of chosen historical bead from miter.

The obtained spectra confirm that the analyzed materials are glass-like character. It was confirmed by peaks at 1036 and $769 \mathrm{~cm}^{-1}$. Actually, the chosen pieces were still glass-like in character, without very severe corrosion, which was proven by the lack of spectra at 3200 $3500 \mathrm{~cm}^{-1}$ suggesting water penetration [4].

\section{Scanning electron microscopy and chemical analysis}

The next beads (taken as a whole) were analyzed by SEM and EDS, including quantity chemical analysis by a non-destructive method using SEM, type JSM-5400 Jeol.

The scanning electron microscopy observation - Fig. 4 and Fig. 5 - points to the irregular shape of presented beads.

They are proof of a higher technological level of bead production. There are some surface irregularities, which are probably due to mechanical surface damages. But, the chemical analysis EDS for chosen points on both the bead surfaces are very similar to each other. Results done by EDS are presented in Fig. 6 and Fig. 7. This data was obtained during the initial stage of the glass corrosion process, pointed out to beginning surface deterioration.

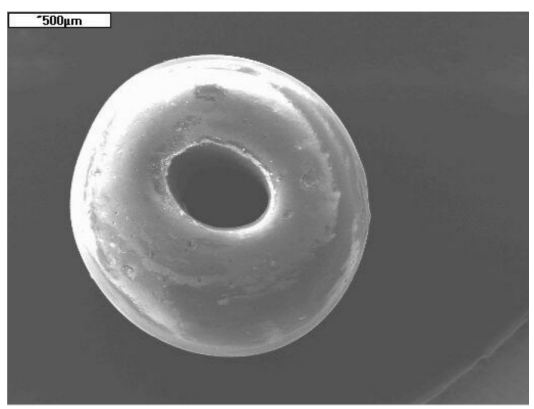

Fig. 4. SEM of original bead.

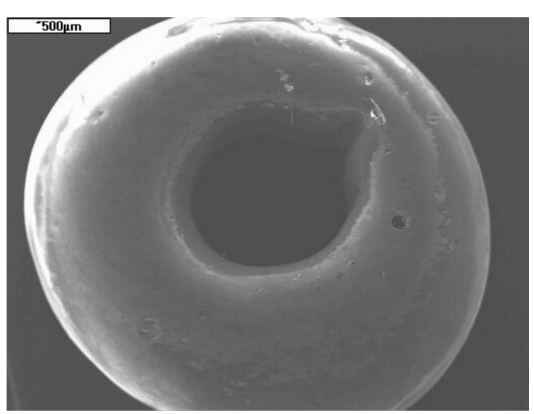

Fig. 5. SEM of original bead.

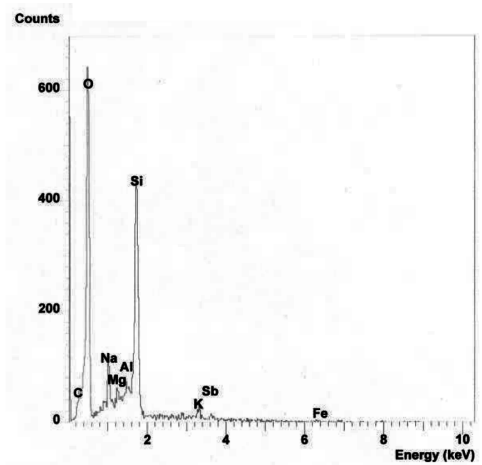

Fig. 6. EDS for chosen point from Fig. 4.

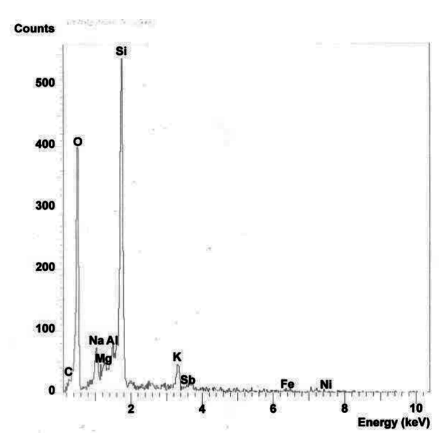

Fig. 7. EDS for chosen point from Fig. 5. 
This is silica gel layer creation, which is the first step in the glass corrosion process, due to water activation, or a higher level of local humidity $[2,6,7]$. There are also places (see Fig. 8), which are the beginning of the ion exchange process between glass and the local surroundings.

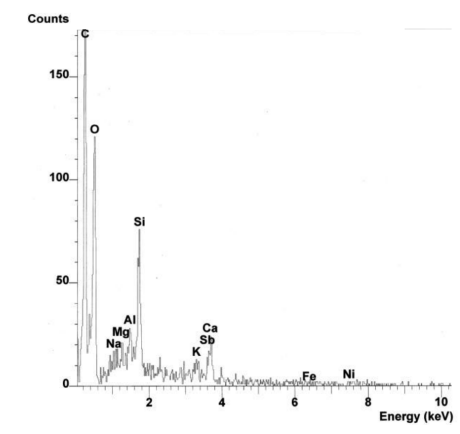

Fig. 8. EDS for chosen point from Fig. 5.

Moreover, the carbon concentration shown in Fig. 8 proved presence of its particle on the bead surface.

It should be emphasized here that the sample was not covered by any media. That is why carbon could originate only from the outside atmosphere.

The second bead borrowed from museum was tested by SEM, which is presented in Fig. 9 with $350 \times$ enlargement. The picture presented $853 \mu \mathrm{m}$ width of observed area. The obtained chemical analyzed data refer to penetration of the depth by about $1 \mu \mathrm{m}$.

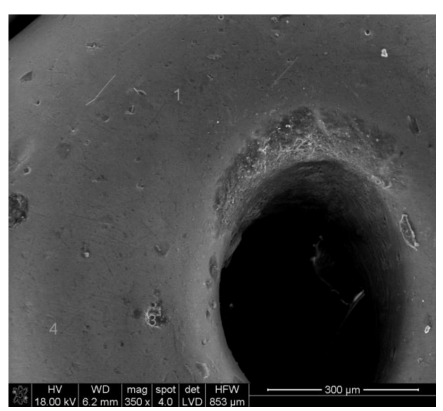

Fig. 9. SEM of glass bead.

The biggest mechanical changes are observed inside of the hole. It could be caused by thread, used for attachment the bead to the fabric.

Additionally, EDS analyses were done for points: 1, 2, 3,4 , presented in SEM picture (Fig. 9).

All these points showed silica gel presence. Moreover, point 1 on the bead surface points on leached alkali (small alkali amount), a little of $\mathrm{Mg}$ and tiny amount of iron (Fig. 10). It is similar information, found at the point 4 . There is also very small amount of copper and not too much carbon. The highest amount of carbon was localized at point 2 and at point 3 . It could be caused by deposit of $\mathrm{CaCO}_{3}$, due to reaction between calcium (from the beads) and carbon dioxide from the atmo-

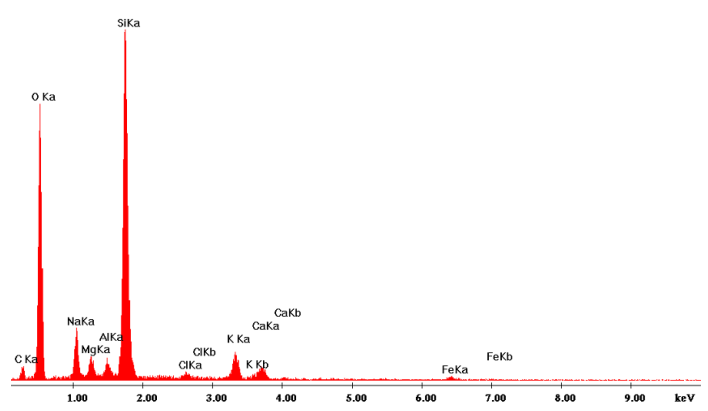

Fig. 10. EDS for point 1 from Fig. 9.

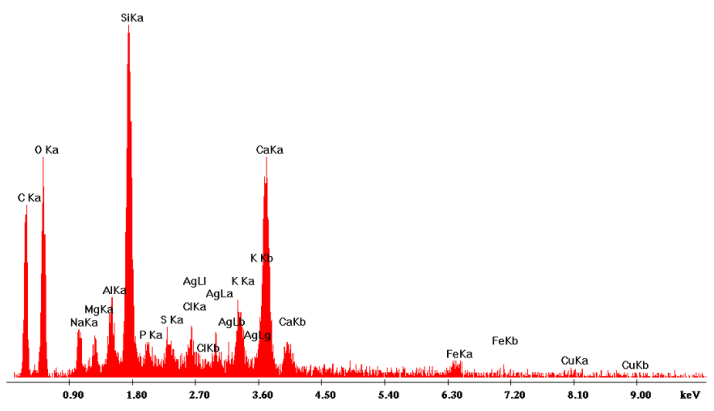

Fig. 11. EDS for point 2 from Fig. 9.

sphere. High amount of calcium and carbon was proved at point 3 (Figs. 11 and 12), which refers to visible deposit on the surface. Situation of such accumulation was very well visible inside of bead's hole [8]. Copper was detected at points 2,3 , and 4 (Fig. 13). These repeated data suggested that copper, partly with mentioned above iron was used as coloring agent. It is hard to prove another function of iron. Probably it was not added intentionally, but inserted into the batch with other raw materials as their impurities. Presence of sulphur can be interpreted as a local environmental activity.

It should be emphasized that we analyze only surface, which was partly deteriorated. The presence of very high amount of oxygen (as well as in atomic and weight scale) confirmed beginning of corrosion process. Created silica gel, consists of high amount as well as oxygen and relative

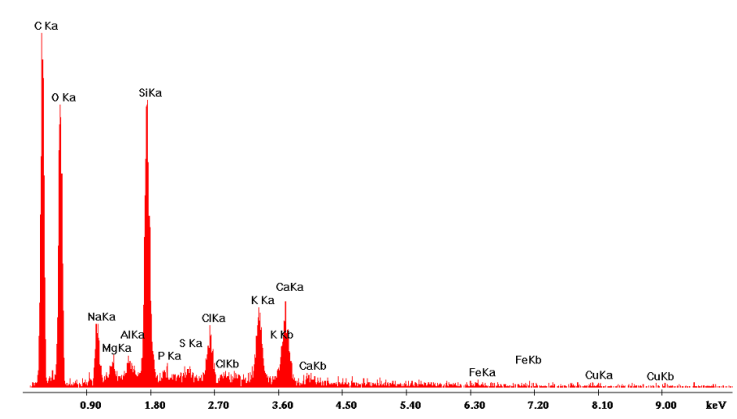

Fig. 12. EDS for point 3 from Fig. 9. 
high amount of silica. That is why in this layer is not too much alkali. It was due to leaching reaction between the glass and surrounding water (or humidity).

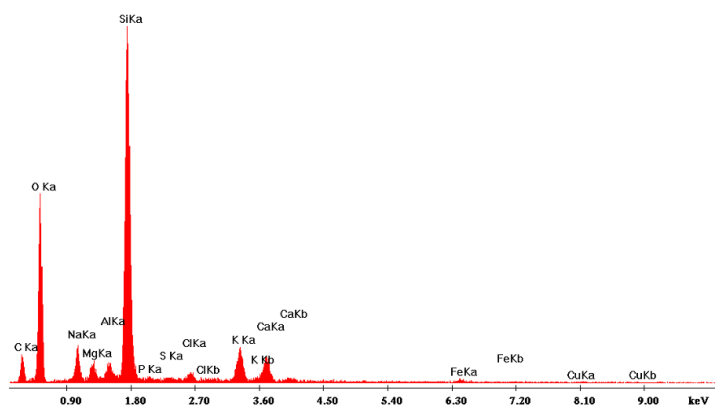

Separately, semi-quantity chemical analyses have been done for each presented above points. Results are presented in Table.

Usually analyzing of glass components is related to a few methods proposed by Szczapowa, Dekówna, or Bezborodow [9]. According to Szczapowa sodium-potassium glasses have been characterized by comparison the following glass elements sums: $\mathrm{Na}_{2} \mathrm{O}+\mathrm{K}_{2} \mathrm{O}$ to $\mathrm{CaO}+\mathrm{MgO}$.

In the case of testing very small analyzing material it is hard to get many data, to make comparison diagnostics to estimate approximate dating or define its origin.

Fig. 13. EDS for point 4 from Fig. 9.

Chemical analyses by EDS for points 1-4 of glass bead presented in Fig. 9. TABLE

\begin{tabular}{|c|c|c|c|c|c|c|c|c|}
\hline \multirow{2}{*}{ Element } & \multicolumn{2}{|c|}{ Point 1} & \multicolumn{2}{|c|}{ Point 2} & \multicolumn{2}{|c|}{ Point 3} & \multicolumn{2}{|c|}{ Point 4} \\
\hline & wt\% & at. $\%$ & wt\% & at.\% & wt $\%$ & at. $\%$ & wt $\%$ & at. $\%$ \\
\hline $\mathrm{C} K$ & 3.61 & 5.72 & 18.89 & 30.28 & 30.19 & 41.08 & 7.99 & 12.71 \\
\hline $\mathrm{O} K$ & 57.26 & 68.13 & 37.59 & 45.23 & 44.92 & 45.89 & 50.24 & 60.04 \\
\hline $\mathrm{Na} K$ & 5.07 & 4.2 & 2.82 & 2.36 & 3.11 & 2.21 & 3.68 & 3.06 \\
\hline $\operatorname{Mg} K$ & 1.51 & 1.18 & 1.3 & 1.03 & 0.64 & 0.43 & 1.38 & 1.08 \\
\hline Al $K$ & 1.13 & 0.79 & 2.24 & 1.6 & 0.64 & 0.39 & 1.25 & 0.88 \\
\hline Si $K$ & 25.3 & 17.15 & 12.63 & 8.66 & 9.15 & 5.33 & 26.51 & 18.05 \\
\hline $\mathrm{P} K$ & & & 0.8 & 0.5 & 0.38 & 0.2 & 0.07 & 0.04 \\
\hline $\mathrm{S} K$ & & & 1.08 & 0.65 & 0.46 & 0.24 & 0.14 & 0.08 \\
\hline $\mathrm{Cl} \mathrm{K}$ & 0.65 & 0.35 & 1.33 & 0.72 & 1.97 & 0.91 & 0.72 & 0.39 \\
\hline $\operatorname{Ag} L$ & & & 2.27 & 0.4 & & & & \\
\hline $\mathrm{K} K$ & 2.69 & 1.31 & 3.03 & 1.49 & 3.36 & 1.41 & 3.61 & 1.77 \\
\hline $\mathrm{Ca} K$ & 1.59 & 0.76 & 11.93 & 5.73 & 3.78 & 1.54 & 2.95 & 1.41 \\
\hline Fe $K$ & 1.2 & 0.41 & 2.47 & 0.85 & 0.62 & 0.18 & 1.09 & 0.37 \\
\hline $\mathrm{Cu} K$ & & & 1.63 & 0.49 & 0.79 & 0.2 & 0.38 & 0.11 \\
\hline Total & 100 & 100 & 100 & 100 & 100 & 100 & 100 & 100 \\
\hline
\end{tabular}

Chemical analysis data for chosen surface points allowed us to estimate relations among glass elements.

Oxygen and silica are in the highest concentration. This phenomenon has been observed in previous test, too. It is due to created silica-gel layer on the glass surface. All measurements were done deep inside up to $1 \mu \mathrm{m}$.

The next element: presence of carbon was proved on the glass surface. It was in high differentiated concentrations, in comparison with other elements. It is referred to especially to one sample where the values were following: $5.72 \%, 12.71 \%, 30.28 \%$, and $41.08 \%$ at a distance of $853 \mu \mathrm{m}$. In this area there are visible stratifications, created due to corrosion, induced by surrounding atmosphere elements.

The calcium is the next element presented in high amount. There are some points on the surface, covered by white deposit created by reactions between leached elements from glass and surrounding element. The sulphur has been found, too, in the three - from four - analyzed points. The alkali: sodium and potassium are found, too. Sodium is dominating, which suggested glass character. Actually alkali concentration is different, which means inhomogeneity in glass mass. This caused different corrosion reactions with surrounding elements.

Very small amount of phosphate has been detected only at the the points 2,3 and 4 . It could be concluded that phosphate was added to the raw material batch, as an opacity agent. Analysed bead is not transparent glass. This object has never been preserved in the soil, and surrounding of the place of its exposition was far from industry area. That is why phosphate is not due to atmosphere compound activity.

It should be emphasized here that tested glass is very old with very low durability. That is why corrosion has happened. Present glass stage could be caused by previous situation. Corrosion could be even incipient, but 
is still continuing. Because of lack of information about the origin of glass it was impossible to define the degree of deterioration during seven ages.

The obtained data allowed us to conclude that the miter was occasionally exposed in the church during mess [1]. It was a reason to be influenced by the burning of incense and the lighting of candles.

The same results were obtained after testing other glass objects in the church, like: XIVth c. stained glass windows, glass decorations from the XVIIIth. c. picture of St. Mary [4]. The intensity of the soot deposit was in strong correlation with the humidity level in the area. Actually, it refers to all places where glass monuments were as well as exposed as storage [5, 10].

\section{Atomic force microscopy}

Moreover, testing of glass morphology was done by AFM (as a non-destructive method), type Microscope Multi View 1000F.

AFM provides high resolution images of surfaces, without any conductive or other complicated sample preparation. AFM proved to be an appropriate tool for imaging the structure on a nanometric scale of glass [5, 11]. Few pictures were taken by AFM from different areas of the beads. The two pictures are presented below: Fig. 14 and Fig. 15.

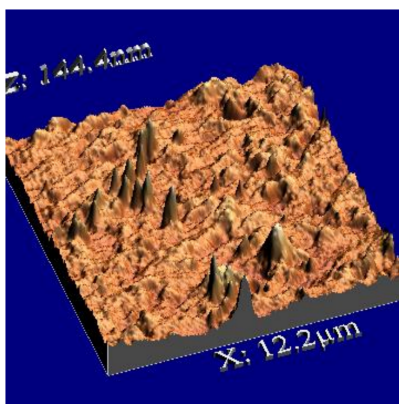

Fig. 14. AFM of chosen area of original bead.

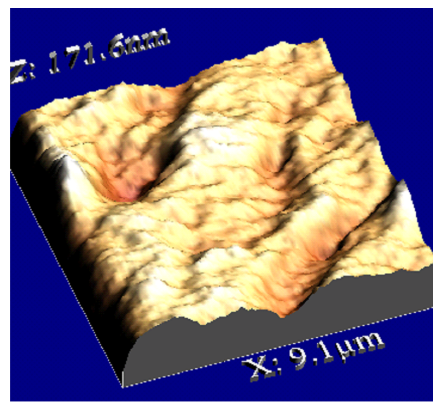

Fig. 15. AFM of chosen area of original bead.

Figure 14 is for the bigger bead, where the observed area is: $22.2 \times 12.2 \mu \mathrm{m}^{2}$ and the highest point due to created deformation equals $144 \mathrm{~nm}$ at the average height of $53.3 \mathrm{~nm}$.

The observed surface changes on the bead surface were created due to many reasons. New forms: pitting or surface corrosion deposit could be created during the formation process or because of their very small scale could be caused by some corrosion process, even at the beginning stage. This was determined by the discovery of very low metrical differences (in nanometric scale) of the preserved images of the glass patterns on the surface beads.

Because AFM provides us with a value of average surface roughness, it was also calculated. The value $10.39 \mathrm{~nm}$ has been found. But the other observed area has been changed due to different processes and pointed to the bigger value for the highest point $131.9 \mathrm{~nm}$, $139.5 \mathrm{~nm}, 166.1 \mathrm{~nm}$. Consequently, the average roughness for these surface is bigger and equals $26.66 \mathrm{~nm}$, $22.23 \mathrm{~nm}$ and $34.05 \mathrm{~nm}$.

The second bead is presented in Fig. 15. This surface does not look so strange, but the average roughness value is much higher than for the first bead. It equals to $19.41 \mathrm{~nm}$. The highest point is at $171 \mathrm{~nm}$, but average height is $102.2 \mathrm{~nm}$.

Moreover, some empty frames for jewellery stones have been filled by wax. The fulfillment under sequins, done by brownish wax was very well preserved. It could be supposed that fulfillment was used to keep decoration stable. This method has been known and written by Mnich Teofil [12]. The wax was tested by another analysis [3]. All decorative details like stones, gold sequins were covered by thick dust layer.

\section{Discussion and results}

Carried out analyses indicate that the decoration elements belong to the glass-like material. Their irregular shape was similar to glass beads. Because of the very small size, round shape and central hole, they represent high level of technology of glass bead production. They were done by hand, which is recognized by irregular shape of internal hole, typical for coral shape. But it is also confirmed improvement in bead production. This developed production form was important to create a better decoration and gives possibility for stronger bead attachment to the fabric.

Data from EDS confirmed carbon presence on the glass surface which confirmed our hypothesis. It means that the reliquary with the head of a holy person - according to the rules of the Roman Catholic church - was decorated by the miter. This "Cracow miter", tested in this research was a souvenir after St. Stanisław bishop canonization and could be used for his reliquary. The carbon, as well as some amount of wax (found by macroscopic observation) on the cornu tituli confirms this fact.

Information from AFM data confirmed presence of some surface irregularities, like very small convexities, due to not uniformly silica gel layer, proven earlier by EDS. It could be caused by glass mass inhomogeneity 
and differentiated glass surface tendency to react with humid penetration. These changes were done on small area and on a low scale, but step by step it was developed over time. That is why this discovery should be taken into consideration by curators. Local parameters, especially those which concern humidity levels will influence not only fabric, but also glass elements. It is important complementary information to design sustainable conservation conditions for such unique historical object.

\section{References}

[1] B. Kalfas, catalogue of exhibition: Sources of Kraków spirit culture, Kraków 2007, p. 69 (in Polish).

[2] J. Olczak, Glass production in Poland in the early Middle Ages, Ossolineum, Warszawa 1968 (in Polish).

[3] M. Rogóż, Expert's report on mitra, Kraków Academy of Art, Kraków 2007 (in Polish).
[4] E. Greiner-Wronowa, Ph.D. Thesis, Kraków 1999.

[5] E. Greiner-Wronowa, Ceramics, Pol. Ceram. Bull. 85, 237 (2004) (in Polish).

[6] E. Greiner-Wronowa, L. Stoch, Glass Technology 43C, 84 (2002).

[7] E. Greiner-Wronowa, Ceramics, Pol. Ceram. Bull. 103/2, 1291 (2008) (in Polish).

[8] E. Greiner-Wronowa, Ceramics, Pol. Ceram. Bull. 103/2, 1293 (2008) (in Polish).

[9] M. Dekówna, Glass in the early Middle Ages, Ossolineum, Warszawa 1980 (in Polish).

[10] E. Greiner-Wronowa, Advanced Materials Research, Trans Tech Publications Ltd., Switzerland 2008, p. 505 .

[11] E. Redlein, G. Frischat, J. Non-Cryst. Solids 222, 69 (1997).

[12] T. Prezbiter, Diversarum Artium Schedula, Benedictines, Kraków 1998. 